\title{
The Idiom Principle Revisited
}

\section{${ }^{1, * A N N A}$ SIYANOVA-CHANTURIA and ${ }^{2}$ RON MARTINEZ}

\author{
${ }^{1}$ Victoria University of Wellington, ${ }^{2}$ San Francisco State University
}

*E-mail: anna.siyanova@vuw.ac.nz

\begin{abstract}
John Sinclair's Idiom Principle famously posited that most texts are largely composed of multi-word expressions that 'constitute single choices' in the mental lexicon. At the time that assertion was made, little actual psycholinguistic evidence existed in support of that holistic, 'single choice', view of formulaic language. In the intervening years, a number of studies have shown that multiword expressions are indeed processed differently from novel phrases. This processing advantage, however, does not necessarily support the holistic view of formulaic language. The present review aims to bring together studies on the processing of multi-word expressions in a first and second language that have used a range of psycholinguistic techniques, and presents why such research is important. Practical implications and pathways for future research are discussed.
\end{abstract}

\section{INTRODUCTION}

Human language is thought to be original and highly creative. However, while we undoubtedly can exercise its creative potential, we do not necessarily do so. Much of the language we experience on a daily basis is largely 'formulaic', or 'prefabricated', rather than completely novel and newly assembled on each utterance, word-by-word. In English, we tend to wish someone a good morning, rather than other plausible possibilities, such as a pleasant, fine, or enjoyable morning. We recognise that the meaning of We might as well have dessert changes if the phrase is formulated as We might have dessert as well, or even As we might well have dessert-even though it is only the way in which those words recombine that changes, and not the words themselves. Despite the potentially infinite creativity of language, many words tend to co-occur with some words more often than with other, seemingly synonymous ones, and those combinations and recombinations often appear to be differentially represented in the mental lexicon. In the present article, we will refer to such recurrent word combinations as multi-word expressions (MWEs), and the nature of that 'differential representation' will be reviewed in greater depth.

Very loosely, MWEs can be defined as (semi-)fixed, recurrent phrases, such as collocations (strong tea), binomials (black and white), multi-word verbs (put up with), idioms (spill the beans), proverbs (better late than never), speech formulae (What's up), lexical bundles (in the middle of), and other types. From a probabilistic viewpoint, MWEs are combinations of words that co-occur more often than would be expected by chance alone (Manning and Schutze 1999). Crucially, MWEs are pervasive in language; they are typically found to 
comprise anywhere from 20 to $>50$ per cent of spoken and written nativespeaker discourse (Sorhus 1977; Howarth 1998; Biber et al. 1999; Erman and Warren 2000; Foster 2001). Count figures vary depending on how one defines a MWE. According to Pollio et al. (1977) and Glucksberg (1989), four multiword sequences are produced by a native speaker in every minute of spoken discourse. Biber et al. (1999) report that multi-word speech constituted 28 per cent of the spoken and 20 per cent of the written discourse analysed. Erman and Warren (2000) and Howarth (1998) estimated that multi-word speech amounted to 52.3 and 40 per cent, respectively, of the written discourse they looked at.

MWEs have been studied extensively by theoretical, applied, and corpus linguists. Thus, we have a notion of what the different types of MWEs are and even (roughly) how frequently they occur in language. However, relatively little empirical research has been done on on-line processing of MWEs. ${ }^{1}$ It has been found that language users notice, learn, and store frequency and predictability information that is encoded in phrasal units (Bannard and Matthews 2008; Arnon and Snider 2010; Siyanova-Chanturia et al. 2011b). It has been hypothesised that this is because it is easier and more economic to remember and use language in chunks rather than as a combination of single words (Wray 2002). Sinclair (1991) was one of the first to theorise on this phenomenon, in what he referred to as the 'Idiom Principle':

The principle of idiom is that a language user has available to him or her a large number of semi-preconstructed phrases that constitute single choices, even though they might appear to be analyzable into segments. (Sinclair 1991: 110)

However, important empirical evidence for the main tenets of the Idiom Principle, particularly with respect to the notion of holistic processing, or what Sinclair describes as 'single choices', is still lacking, and even more so when it comes to processing in the $\mathrm{L} 2 .^{2}$

The present review aims to bring together a range of studies that deal with MWE on-line processing in a first (L1) and second (L2) language with the aim of synthesising psycholinguistic evidence related to the assumptions that underpin the Idiom Principle. The article is structured as follows: after presenting some arguments for the practical importance of empirical investigation into the processing of MWEs, we focus on the two most important (from the online processing perspective) characteristics of MWEs-frequency and predictability. We then review a range of MWE processing studies in L1 and L2. Finally, theoretical and practical implications, as well as pathways for future research, are discussed.

\section{WHY INVESTIGATE MWE PROCESSING}

Sinclair was probably not the first, and certainly not the last, to theorise about the psycholinguistic reality of MWEs. One of the most often cited definitions of 
MWEs, called formulaic sequences by Wray (2002), includes assertions reminiscent of the Idiom Principle:

(A formulaic sequence is) a sequence, continuous or discontinuous, of words or other elements, which is, or appears to be, prefabricated: that is, stored, retrieved whole from memory at the time of use, rather than being subject to generation or analysis by the language grammar. (Wray 2002: 9)

Put another way, it can be said that what Sinclair calls 'semi-preconstructed', Wray terms 'prefabricated'; what Sinclair describes as constituting 'single choices', Wray posits as 'retrieved whole from memory'. What both statements have in common are assertions regarding the holistic nature of MWE processing; what, arguably, each lacks is clear and strong empirical evidence to back them. The lacuna left by this paucity in the literature regarding MWE processing has detracted from their more systematic inclusion and fuller integration into pedagogy: a place for the Idiom Principle, or concepts like it, is only likely to be given more serious consideration in the classroom when its relevance to language acquisition is better understood. For that reason, this article aims to provide a synthesis of the some of the relevant literature to date that has addressed-directly or indirectly-the following questions:

- Q1: What evidence is there that MWEs are processed differently from novel strings of language?

- Q2: What differences are there between the processing of MWEs in a first language versus a second language?

- Q3: What are the theoretical implications of the literature reviewed for Q1 and Q2 with respect to the nature of the mental lexicon?

- Q4: What are the practical implications of the discussions addressing Q1 and Q2?

A better understanding of the answers to the above questions may lead to enhanced language pedagogy, among other things (e.g. language testing and textbook development). If, for instance, it can be asserted on the strength of empirical evidence that (i) the Idiom Principle does offer important processing advantages, and that (ii) these advantages can also be enjoyed by non-natives and can be achieved as long as they do ' $\mathrm{X}$ ' amount of ' $\mathrm{Y}$ ' (for example,

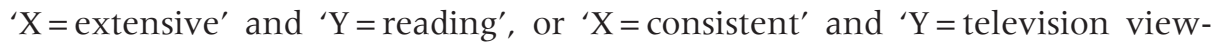
ing'), then what needs to be explored and discussed are the best ways to encourage and develop that ' $\mathrm{X}$ ' and ' $\mathrm{Y}$ '.

More generally, the study of the processing and representation of MWEs has important theoretical implications for a broader debate about the nature of the mental lexicon. The finding that MWEs are integral building blocks of language undermines traditional distinctions between the lexicon and grammar, and raises questions about the way linguistic knowledge is learnt and subsequently represented in the lexicon of a native speaker and a L2 learner.

In the sections that follow, evidence will be reviewed that-at least at the time of writing-represents the state of the art with respect to what is known 
about the way in which MWEs are processed, and concomitant issues. It is not the intention here to show that the answer to the question How are MWEs processed? has, in fact, been answered, but rather to, much like one would do when halfway to completion of a jigsaw puzzle, take a step back and look at what has been done and what is missing to consider how to fill the gaps.

\section{FREQUENCY AND PREDICTABILITY OF MWES}

There are many different types of MWEs: some are short (strong tea), others can span over a sentence (you can't judge a book by its cover); some are literal (time and money), others are figurative (spill the beans); some allow syntactic modification, such as passivisation (He finally spilled the beans $\rightarrow$ The beans were finally spilled), others do not (John kicked the bucket $\rightarrow{ }^{*}$ The bucket was kicked by John). To that extent, MWEs are rather heterogeneous. However, what MWEs generally have in common is that they are relatively frequent ${ }^{3}$ (and, as a result, highly familiar) and predictable to a native speaker word clusters. Below, we discuss frequency and predictability and what role they play in MWE on-line processing.

\section{Frequency}

Frequency plays a central role in natural language processing. According to Ellis (2002), language processing is tuned to input frequency because language users are highly sensitive to the frequencies of linguistic events in their experience (also see Bybee 1998). Indeed, lexical frequency effects are one of the most robust in psycholinguistic research (Balota and Chumbley 1984; Rayner and Duffy 1986; Monsell et al. 1989). As argued by Bod et al. (2003: 10), 'frequency effects are everywhere'. Some researchers have gone as far as to suggest that frequency may be the main factor responsible for the organisation of the lexicon (Forster 1976).

Although Wray (2002) regards frequency as one of the most salient and determining characteristics of multi-word speech, phrasal frequency has, nevertheless, received surprisingly little attention in psycholinguistic research (relative to the vast amount of research that has looked at the effects of lexical, i.e. single word, frequency in language processing) and still remains, in the words of Jurafsky (2003), an important unsolved problem. As Jurafsky (2003) points out, the frequency of complex constructions (of any length or internal structure) is much lower than that of single words, and hence frequency effects in such larger units are harder to observe and to investigate.

According to usage- and exemplar-based approaches ${ }^{4}$ to language acquisition, processing, and use, our mental representations are determined purely by language use, or, in other words, by frequency (Bybee 1985, 1995, 1998, 2006; Langacker 1987; Goldberg 1995, 2006; Bod 1998, 2006; Croft 2001; Pierrehumbert 2001; Tomasello 2003, 2006; Abbot-Smith and Tomasello 2006; also see Ellis 2011, 2012). Whenever a linguistic unit (a word or a phrase) 
is recalled from memory, it is thought to activate nodes in the lexicon; subsequently, the frequency of activation of this unit affects its representation in the mental lexicon (Croft and Cruse 2004). Thus, new experiences with a word or a phrase are not decoded and then discarded; rather, they shape our memory representations (Bybee 2006). Every linguistic token that is encountered by a language user is believed to be registered in memory, which leads to language processing operating with a vast set of exemplars (Bybee 2006; Goldberg 2006; Ellis 2012). Such exemplars could be words, phrases, or grammatical constructions. As Bod (2006) notes, without this seemingly massive storage of various exemplars, frequencies can never accumulate and, thus, conventional ways of speaking cannot be learnt. Therefore, language should be viewed as a statistical accumulation of experiences that changes every time a particular utterance is encountered (Bod 2006; also see Ellis and O'Donnell 2012). Most importantly, frequency has often been claimed to have bearing on the way in which MWEs are processed:

[A]s a particular string grows more frequent, it comes to be processed as a unit rather than through its individual parts. As it is accessed more and more as a unit, it grows autonomous from the construction that originally gave rise to it. (Bybee 2006: 720)

In support of the assertion of frequent MWEs being 'processed as a unit', Bybee (2006) offers examples such as going to (e.g. I'm going to think about it), now usually taught as a grammatical marker to refer to the future in instructed English language contexts, but which originally only literally meant go + to While this etymological evidence can seem compelling, it is, nonetheless, limited and indirect. We will return to further evidence of these frequency effects later in the article.

\section{Predictability}

Another key feature of MWEs is predictability. On hearing or reading the beginning of an idiom (tie the ...), a popular saying (better late...), a collocation (extenuating....), or a binomial (fish and...), a mature language user is bound to complete it with the most likely word or words (knot, than never, circumstances, and chips, respectively). According to probabilistic language models, statistical information about the co-occurrence of words is represented in the speaker's mind (Jurafsky 1996; Gregory et al. 1999; Seidenberg and MacDonald 1999; McDonald and Shillcock 2003a,b). McDonald and Shillcock (2003a,b) contend that the large amounts of language that a native speaker encounters on a daily basis represent a rich source of statistical knowledge about this language. Thus, not unlike the predictive text algorithms designed to facilitate typing on smartphones and internet search engines, the brain is capable of using this statistical information during language processing to estimate the probability of appearance of certain words. Importantly, it is 
pointed out that integrating a word into one's lexicon also involves encoding its surrounding context (McDonald and Shillcock 2003b).

It has been found that a word's predictability within a given context (sentential or phrasal) impacts the ease with which it is comprehended on-line (Balota et al. 1985; Rayner and Well 1996; Reichle et al. 1998; Gregory et al. 1999; McDonald and Shillcock 2003a,b; Engbert et al. 2005; Pickering and Garrod 2007). This is because, on seeing word $n$, comprehenders predict word +1 . Facilitation associated with the processing and integration of highly predictable words has been accounted for in the models of reading, specifically, in the context of one particular methodology-eye movements. According to Reichle et al. (1998) and Engbert et al. (2005), there is a close link between eye-movement control and high-level cognitive processes. In other words, eye-movement patterns are highly dependent on such properties of a word as frequency and predictability because they represent readers' knowledge of and experience with language.

In the following sections, studies that have attempted to more directly observe the psycholinguistic evidence for frequency and predictability effects as they relate to MWEs, will be reviewed.

\section{PROCESSING OF MWES IN A FIRST AND SECOND LANGUAGE}

Researchers have long noted that given their frequency (and, hence, familiarity) and predictability, various instances of multi-word speech serve as ideal candidates for the investigation of phrasal processing and representation in L1 and L2. To this end, a number of methodologies and paradigms have been used, such as behavioural measures (self-paced reading, moving window paradigm, elicitation tasks) and eye tracking. In addition, two modalities have been investigated: comprehension and production. In what follows, we review a number of studies (with healthy L1 and L2 populations) that have used behavioural measures and eye tracking in the investigation of MWE processing and representation in L1 and L2.

\section{Comprehension of MWEs}

As was mentioned earlier in the article, there are many types of MWEs, and some are much more common than others. Indeed, as pointed out in Martinez and Schmitt (2012), some MWEs are so common that they may not even stand out to native speakers as having MWE status (e.g. no one, each other, used to, a number of, rather than). However, perhaps, in part due to their salience, atypicality, and, ironically, relative rarity (see Footnote 3), the type of MWEs that has received by far the greatest amount of attention is idioms. Arguably, this is because many of them can be interpreted figuratively and literally (so called ambiguous idioms). Much of the idiom research to date has focused on the order of activation of idioms' figurative and literal meanings, and on the 
processing of idiomatic phrases versus novel strings of language. A number of models have been put forward that deal with figurative versus literal meaning processing in Ll (Bobrow and Bell 1973; Swiney and Cutler 1979; Cacciari and Tabossi 1988). According to the lexical representation hypothesis by Swinney and Cutler (1979), idioms are represented in the mental lexicon akin to morphologically complex words; it is argued that the figurative meaning becomes activated first (because computation of the literal reading is more time consuming than the retrieval of the figurative one). According to another theory-the configuration hypothesis by Cacciari and Tabossi (1988)-the individual literal readings of words within an idiom are activated until the idiomatic key' is reached; then, the idiomatic configuration surfaces and the figurative reading is accessed as plausible, while the literal one is rejected as implausible. Others have also looked at the processing of idioms versus matched novel phrases. In Swinney and Cutler (1979), idioms (break the ice) enjoyed a processing advantage relative to literal control phrases (break the сир). This was further supported by the work of Gibbs (1980) and Gibbs and Gonzales (1985). Finally, according to the idiom decomposition hypothesis (Gibbs et al. 1989), idiom comprehension is determined by whether it is decomposable or non-decomposable; decomposable idioms (pop the question) should be processed faster than control phrases (ask the question), while non-decomposable idioms (kick the bucket) should exhibit no processing advantage over control phrases (fill the bucket).

Various aspects of idiom on-line processing have also been investigated with regard to L2 learners. Using a cross-modal priming paradigm, Cieslicka (2006) had non-native participants listen to neutral sentences containing familiar idioms (George wanted to bury the hatchet soon after Susan left). Participants were asked to perform a lexical decision task on one of the following: a word associated with the figurative meaning (forgive), or its control word (gesture); a word associated with the literal meaning (axe), or its control word (ace). Cieslicka (2006) observed faster response times to the words associated with the literal meaning than to those associated with the figurative meaning. This was taken to suggest that in L2 idiom comprehension, literal idiom renderings are activated before the figurative ones. In a similar vein Conklin and Schmitt (2008) investigated idiom comprehension in L1 and L2 when a biasing context preceded the idiom. In a self-paced moving-window reading experiment, they found that idioms were read more quickly than control phrases both in Ll and L2. Critically, no differences were found between figurative and literal readings for either participant group. It needs to be pointed out, however, that Conklin and Schmitt (2008) used a within subject design (i.e. each participant was exposed to all three, rather than one, experimental manipulations), which may have influenced the pattern of results observed.

More recently, studies have looked at idiom comprehension in L1 and L2 using an eye-movement paradigm. In one of the first such studies, Underwood et al. (2004) investigated idiom comprehension in L1 and L2. They compared 
fixations that fell on the terminal word within an idiom (e.g. honesty is the best policy) and the same terminal word within a novel phrase (e.g. it seems that his policy of ...). A processing advantage for idioms was found for native participants, but not non-native speakers. An interesting question with regard to (ambiguous) idioms is how L1 and L2 speakers process the figurative and literal meaning. The above study, although informative in terms of idiomatic versus novel phrase processing in L1 and L2, does not address an important issue of figurative versus literal idiom meaning processing. In a more recent eye tracking study, this issue is addressed with respect to both L1 and L2 speakers. Siyanova-Chanturia et al. (2011a) investigated idiom processing in a biasing story context by native and non-native English speakers. They looked at idioms used figuratively (e.g. at the end of the day-'eventually'), same idioms used literally (e.g. at the end of the day-'in the evening'), as well as matched novel phrases (e.g. at the end of the war). The study confirmed the previous finding that native speakers read idioms more quickly than novel language. Crucially, in the presence of a disambiguating context, native speakers did not read the lower frequency literal meaning more slowly than the higher frequency figurative one. A different pattern of results was observed for nonnatives. Proficient L2 speakers did not read idioms more quickly than novel phrases. Interestingly, they required more time to retrieve figurative senses than literal ones, even when the biasing context supported the figurative rendering. This slow down was mostly evident in the analysis before the recognition point (the point at which a phrase becomes uniquely identifiable as an idiom).

It is, perhaps, not surprising that of the many different types of MWEs, idioms are by far the most well researched ones, not least due to their idiosyncrasy, atypicality, and salience, as well as the availability of two distinct meanings-figurative and literal (in the case of ambiguous idioms). However, idioms aside, other, qualitatively and quantitatively different, types of MWEs have also been investigated, such as, for example, collocations, binomials, lexical bundles, and frequent compositional phrases. One of the first studies on phrasal processing was done by Sosa and MacFarlane (2002), who monitored the particle of in two-word collocations that varied in frequency (e.g. sort of, kind of). It was found that reaction times to of in higher frequency phrases were slower than in lower frequency ones. According to Sosa and MacFarlane (2002), this suggested that frequent phrases were treated as a unit, which hindered access to their individual parts.

In a more recent study, Arnon and Snider (2010) investigated the role of phrasal frequency in the comprehension of four-word compositional phrases (don't have to worry). Participants performed a phrasal decision task, where they decided as quickly as possible whether the target sequence was a plausible phrase in English. They found that higher frequency phrases were comprehended faster than lower frequency ones, with the frequency of constituent words matched. This led Arnon and Snider (2010) to conclude that language 
users notice, learn, and store frequency information that is represented even in fully compositional phrases.

In a study using comparable stimuli and a self-paced reading paradigm, Tremblay et al. (2011) compared the processing of sentences that contained lexical bundles (e.g. in the middle of the) and matched control phrases (e.g. in the front of the) (lexical bundles were defined as frequently recurring strings of words that often span traditional syntactic boundaries). It was found that sentences with lexical bundles were read faster than sentences with control phrases. In addition, they were more likely to be remembered and recalled correctly, suggesting that the more frequent the phrase, the more likely it is to leave memory traces in the brain.

Unfortunately, outside of the idiom domain, few studies have looked at MWE on-line processing in L2. In a recent study, Siyanova-Chanturia et al. (2011b) examined the processing of frequent phrases in L1 and L2 using an eye tracking paradigm. Their participants read sentences containing binomial expressions (e.g. bride and groom) and their reversed forms (e.g. groom and bride), which were identical in syntax and meaning but differed in phrasal frequency. Using mixed-effects modelling, it was demonstrated that both natives and proficient non-natives were sensitive to phrasal frequencies (frequent vs. infrequent) and phrasal configuration (binomial vs. reversed). No such effect was found for lower proficiency non-natives suggesting that frequency of exposure determines what is represented in the mental lexicon. Siyanova-Chanturia et al. (2011b) took their results to support the view according to which each and every occurrence of a linguistic unit (at the word or phrase level) contributes to its degree of entrenchment in one's memory.

\section{Production of MWEs}

Important evidence for a processing advantage enjoyed by MWEs also comes from production studies. Over thirty years ago, the pioneers of MWE empirical research, Van Lancker et al. (1981) observed that novel phrases had longer durations because they contained more and longer pauses, and that their constituents were spoken more slowly. Similarly, Bybee and Scheibman (1999) and Bell et al. (2003) note that words are phonetically reduced when they are part of a frequent phrase (e.g. I don't know, middle of the). With respect to language production, two recent studies merit our closer attention. In an elicitation task, Janssen and Barber (2012) had participants produce noun + adj, noun + noun, and det + noun + adj phrases. They found that naming latencies were shorter for higher frequency phrases relative to lower frequency ones. Janssen and Barber (2012) concluded that the language processor is sensitive to the distribution of linguistic information beyond individual words. These production results, and the conclusions drawn from them, are remarkably in line with the comprehension findings reviewed above, such as those of Siyanova-Chanturia et al. (2011b) and Arnon and Snider (2010). Finally, Arnon and Cohen Priva (2013) investigated the effect of phrasal frequency 
on phonetic duration (e.g. don't have to worry vs. don't have to wait). Akin to Janssen and Barber (2012), Arnon and Cohen Priva (2013) demonstrated that phonetic durations were reduced in higher frequency phrases relative to lower frequency phrases. The effect was observed in spontaneous, as well as elicited speech, and was not down to the frequency of individual constituents. These findings (together with those of Janssen and Barber 2012) illustrate parallels between comprehension and production in L1. Unfortunately, all of the production studies to date have focused solely on MWE processing in a first language. The mechanisms involved in MWE production in a second language are largely unknown and will remain an important topic for future enquiry.

The above studies differ considerably in terms of the populations used (L1 and L2), modalities adopted (comprehension and production), and methodologies used (eye tracking, self-paced reading, monitoring task, elicitation task, etc.). Critically, the above studies differ greatly with respect to the specific type of MWEs investigated (idioms, collocations, binomials, lexical bundles-MWEs varying in their figurativeness, literality, compositionality, length, and frequency). Despite this heterogeneity, all of the above studies strongly suggest that the human brain is highly sensitive to frequency and predictability information encoded in phrasal units.

Notwithstanding the robustness of and similarities between the findings presented above, as well as their important joint contribution to the theories of language learning and use, vital empirical evidence is still missing. For example, as pointed out above, we know virtually nothing about MWE production in L2. Further, with the exception of Siyanova-Chanturia et al. (2011b), no study has looked at MWE processing with respect to various L2 proficiencies, with most studies looking at L2 speakers as one homogenous (presumably, advanced) group. Siyanova-Chanturia et al. (201 lb) found that more proficient non-native speakers performed akin to native speakers, in that they read MWEs faster than their controls, while less proficient non-native speakers exhibited comparable reading speeds for both phrase types. To fully understand all the underlying mechanisms involved in MWE processing, acquisition, use, it is imperative to map both production and comprehension of various types of MWEs in L1 against L2, as well as more proficient L2 against less proficient L2 (potentially, introducing more than two proficiency levels). These are only some of the gaps, which, we believe, future research should focus on.

\section{THEORETICAL IMPLICATIONS}

The existence of recurrent patterns has long been acknowledged by linguists (Saussure 1916/1966; Firth 1957) and psychologists alike (Miller 1956). While Saussure (1916/1966) proposed that two or more linguistic units can be fused into one, Firth (1957) drew attention to the context-dependent nature of meaning [as he famously said: 'You shall know a word by the company it keeps' (1957: 11)]. In the field of psychology, Miller (1956) has long argued 
that chunking is an important strategy in linguistic processing. In his article on short-term memory limitations, he proposed the following. First, to be able to process linguistic input effectively, one has to operate with larger linguistic units-chunks. Secondly, short-term memory has a capacity of processing seven, plus or minus, two chunks. Thirdly, Miller argued that the span of immediate memory seems to be almost independent of the number of bits per chunk' (Miller 1956: 92). If, indeed, the human brain operates with larger chunks, along with single words, then it becomes apparent that the focus of linguistic enquiry should be not only on single words, but on multiword expressions as well.

Indeed, a more 'phrasal' perspective is gradually starting to gain ground. A view that has recently been gaining popularity is that language users are sensitive to frequency information at different levels (e.g. sublexical, lexical, phrasal, clausal, etc.), and that this information affects the processing of different linguistic material (e.g. morphemes, words, MWEs, clauses, etc.). The studies reviewed in the present article suggest that frequent MWEs are processed faster than matched novel strings by native, as well as non-native, speakers. The fact that multi-word speech is processed quantitatively differently from novel language has two major implications for linguistic theory. The first regards the nature of linguistic representation. It appears that the occurrence of a psychological event, a word or a phrase, leaves a trace in one's memory, which facilitates its further usage. Through recurrence, even highly complex events can become routinised, and as a result, be carried out with less effort [the process known as 'routinisation', or 'automatisation' (Segalowitz 2003)]. The results outlined above suggest that due to their frequency of occurrence, MWEs become automatised to such an extent that they become represented in the mental lexicon. What being 'represented' presupposes is, perhaps, best explicated by Langacker (1987):

A complex structure (e.g. a phrase) that is represented in the lexicon of a native speaker is something that 'a speaker has mastered quite thoroughly, to the extent that he can employ it in a largely automatic fashion, without having to focus his attention specifically on its individual parts or their arrangement' (Langacker 1987: 57).

It is imperative to note, however, that we are not arguing that the findings reviewed above entail that frequent MWEs are stored and processed as unanalysed wholes. The results of the studies reported above, we believe, have implications with regard to the way language is learnt, processed, and represented. However, they cannot be taken to indicate that MWEs are accessed as unanalysed wholes. Moreover, studies have shown that even the most idiosyncratic and arguably 'word-like' of all MWEs-idioms-exhibit evidence of internal structure (Cutting and Bock 1997; Peterson et al. 2001; Konopka and Bock 2009). Regular decompositional analyses have been found to be involved in the processing of idioms not only at the level of syntax (Konopka and Bock 2009), but also at the level of semantics (Sprenger et al. 2006). 
Overall, researchers have largely rejected the idea that idioms are processed in a holistic, word-like, manner (e.g. Cacciari and Tabossi 1988; Gibbs et al. 1989; Titone and Connine 1999). Our proposition is thus that due to their frequency of occurrence, MWEs are represented (i.e. entrenched) in the lexicon of a native speaker, and, to a lesser degree, in the lexicon of a non-native speaker (because the latter would have had less experience with such expressions compared with their native speaker counterparts). The issue of representation does not, in our understanding, equal that of holistic storage. Only future research focusing directly on the issue of holistic retrieval and (un)analysability of MWEs-rather than their representation and the speed of processing-will be able to shed important light on whether or not MWEs are indeed stored and retrieved as holistic, or unanalysed, wholes.

Secondly, the results of the studies have important implications for theories of language learning (Abbot-Smith and Tomasello 2006; Bannard and Mathews 2008; Arnon and Clark 2011; Arnon and Ramscar 2012). Words have traditionally been viewed as primary units of language acquisition in first and second language learning as is implicit in every vocabulary-based assessment of language development in both the L1 and L2, such as the popular Peabody Picture Vocabulary Test, or PPVT (Dunn and Dunn 2007), and often used Vocabulary Levels Test, or VLT (Schmitt et al. 2001). The empirical finding that units above the word level may also serve as units of representation and processing in mature language users entails an interesting possibility with regard to the role that such units play in language learning (this issue will be discussed in the following section).

More generally, the results reviewed in the current article can be taken to support a number of usage-based (Langacker 1987; Goldberg 1995, 2006; Bybee 1998; Tomasello 2003) and exemplar-based (Bod 1998, 2006; Pierrehumbert 2001) approaches to language acquisition, processing, and use. According to the proponents of these theories, frequency effects are present in smaller (morphemes, words), as well as larger units (compounds, compositional phrases, idioms), and, thus, all linguistic material should be represented and processed in a similar way. As Bod (2006) argues, the allocation of representations to linguistic exemplars is accomplished purely on the basis of statistics (i.e. the frequency of occurrence), and, thus, language should be viewed not as a set of specific grammar rules (and neither as two distinct and disjointed entities-the lexicon and grammar), but as a statistical accumulation of linguistic experiences that changes every time a particular word, phrase, or sentence is encountered (Bod 2006; also see Arnon and Snider 2010; Siyanova-Chanturia et al. 2011 b).

\section{THE IDIOM PRINCIPLE AND PEDAGOGY}

The results presented above have important pedagogical implications. It has been widely acknowledged that multi-word speech is ubiquitous and that it plays a fundamental role in both child naturalistic and adult classroom-based 
language learning (e.g. Wray 2002; Meunier and Granger 2008). Its appropriate use has been recognised as a prerequisite for any second/foreign language learner who wants to achieve high proficiency and be accepted in an L2 community. However, it has also been documented that second language learners underuse native-like MWEs and/or tend to use a large number of anomalous word combinations that are grammatically correct but are simply not 'how native speakers say it' (Granger 1998; Howarth 1998; Wray 2002; Nesselhauf 2004; Siyanova and Schmitt 2007, 2008). This may be due to how languages have traditionally been taught, which has resulted from the view that has dominated linguistics in the past decades, namely, that the main unit of language acquisition is the orthographic word. However, if the Idiom Principle is to be considered a plausibly valid construct among native speakers-which seems to largely be the case-then knowledge of 'semi-preconstructed' phrases should be systematically included in language pedagogy. As has been presented in this article, the extent to which such phrases actually 'constitute single choices' for non-native speakers (or native speakers, for that matter) is still not entirely clear. What is clear, however, is that just as MWEs have been shown to have a processing advantage for natives, it may also be the case that deviation from institutionalised forms and their predictability can incur a processing disadvantage.

Such was the conclusion of Millar (2011), who compiled a corpus of 'malformed' formulaic language from Japanese non-native learners of English, that is, word combinations which were semantically plausible and comprehensible, but which were in violation of the Idiom Principle (e.g. cheap cost as opposed to low cost). Using a self-paced reading methodology, Millar was able to show that there was a significant processing lag when native speakers read the malformed MWEs relative to the synonymous and more formulaic counterparts extracted from the 100-million-word BNC. Millar concluded that the study 'clearly shows that learner collocation errors place an increased and sustained cognitive burden on the addressee' (Millar 2011: 145). However, this is still just one study. Although a slightly larger body of evidence exists that native speakers perceive language produced by non-natives that contains MWEs as superior to discourse that is lacking MWEs, or is, in Millar's terms, 'malformed' (Boers et al. 2006; Geluso 2013), the extent to which there is a processing disadvantage that can also lead to, for example, comprehension issues on the part of the reader/hearer of malformed formulations, is an area that is still much ripe for further exploration.

Some headway has been made, however, in recent years with regard to a better systematisation of which MWEs may be especially worth focusing on explicitly. For Academic English, Simpson-Vlach and Ellis (2010) created a list of pedagogically relevant MWEs called the Academic Formulas List (AFL) by applying quantitative statistical measures to the qualitative judgement data. Native speakers were asked to examine a list of commonly recurring word strings ('n-grams') and indicate, using a set of criteria prescribed by Simpson-Vlach and Ellis, which ones they judged to be worth teaching. 
Table 1: Spoken AFL Top 10

\begin{tabular}{|c|c|c|c|c|c|c|}
\hline & & Speech & & Writing & & \\
\hline & & Raw freq. & $\begin{array}{l}\text { Freq. per } \\
\text { million }\end{array}$ & Raw freq. & $\begin{array}{l}\text { Freq. per } \\
\text { million }\end{array}$ & FTW \\
\hline 1 & be able to & 551 & 256 & 209 & 99 & 2.96 \\
\hline 2 & blah blah blah & 62 & 29 & 0 & 0 & 2.92 \\
\hline 3 & this is the & 732 & 340 & 127 & 60 & 2.77 \\
\hline 4 & you know what I mean & 137 & 64 & 4 & 2 & 2.27 \\
\hline 5 & you can see & 449 & 209 & 2 & 1 & 2.12 \\
\hline 6 & trying to figure out & 41 & 19 & 2 & 1 & 2.05 \\
\hline 7 & a little bit about & 101 & 47 & 0 & 0 & 2.00 \\
\hline 8 & does that make sense & 63 & 29 & 0 & 0 & 1.99 \\
\hline 9 & you know what & 491 & 228 & 4 & 2 & 1.99 \\
\hline 10 & the university of Michigan & 76 & 35 & 1 & 0 & 1.98 \\
\hline
\end{tabular}

Through multiple regressions, the researchers arrived at a metric that could predict pedagogically relevant MWEs (or 'formula teaching worth'-FTW), which ended up mostly being mutual information (MI), ${ }^{5}$ with some influence from frequency ( $\beta 0.56 \mathrm{MI}+\beta 0.31$ frequency). Therefore, the items in the $A F L$ are in theory prioritised by this FTW metric (Table 1), with MWEs most likely to be deemed useful listed first.

More recently, Martinez and Schmitt (2012) sought to create a list of MWEs that could complement existing lists of vocabulary, such as the popular and enduring General Service List (West 1953). However, like Simpson-Vlach and Ellis (2010), Martinez and Schmitt (2012) first sought to arrive at a system to prioritise their corpus-derived MWE selections, and ultimately concluded that the selection criteria for such a list should revolve around 'high frequency, meaningfulness, and relative non-compositionality' (p. 304), with the rationale that more opaque MWEs have been shown to cause more difficulty for learners, especially from a receptive standpoint (Nesselhauf 2003; Martinez and Murphy 2011). Their Phrasal Expressions List (or 'PHRASE List'), therefore, is also prioritised by a notion of 'usefulness', in their case operationalised by both frequency and relative semantic opacity (see example in Figure 1).

Such research can be considered helpful in that it provides a tangible way for those involved in pedagogy to try to systematically incorporate MWEs into their instruments and methods. However, reflecting on MWE-related research in both L1 and L2, it could also be argued that the Idiom Principle and its perceived tenets have had researchers missing the formulaic forest for the MWE trees. Maybe it is the case that MWEs, such as those found on the 


\begin{tabular}{|c|c|c|c|c|c|c|}
\hline $\begin{array}{l}\text { Integratod } \\
\text { List } \\
\text { Rank }\end{array}$ & Phrase & $\begin{array}{l}\text { Frequency } \\
\text { (per } 100 \text { milition) }\end{array}$ & $\begin{array}{l}\text { Spoken } \\
\text { general }\end{array}$ & $\begin{array}{l}\text { Written } \\
\text { general }\end{array}$ & $\begin{array}{l}\text { Written } \\
\text { academic }\end{array}$ & Example \\
\hline 107 & HAVE TO & 83092 & $* * *$ & $* *$ & * & I exercise because I have to. \\
\hline 165 & THERE IS/ARE & 59833 & $* * *$ & $* *$ & $* \star$ & There are some problems. \\
\hline 415 & SUCH AS & 30857 & $*$ & $* * *$ & $\star \star \star *$ & We have questions, such as how it happened. \\
\hline 463 & GOING TO (FUTURE) & 28259 & $\cdots *$ & $\cdots$ & $\mathbf{x}$ & I'm going to think about it. \\
\hline 483 & OF COURSE & 26966 & $* * *$ & $* *$ & * & He said he'd come of course. \\
\hline 489 & A FEW & 26451 & $\approx * \star$ & $* *$ & $\star$ & After a fow drinks, she started to dance. \\
\hline 518 & AT LEAST & 25034 & $\cdots *$ & $* *$ & $* *$ & Well, you could email me at least. \\
\hline 551 & SUCH A(N) & 23894 & $* * *$ & $* *$ & * & She had such a strange sense of humor. \\
\hline 556 & I MEAN & 23616 & $\cdots *$ & $\mathbf{x}$ & $\mathbf{x}$ & It's fine, but, I mean, is it worth the price? \\
\hline 598 & ALOT & 22332 & $* * *$ & * & $\mathbf{x}$ & They go camping a lot in the summer. \\
\hline
\end{tabular}

Figure 1: Top 10 items from the PHRASE List (from Martinez and Schmitt 2012)

AFL and the PHRASE List, are really only tips of a broad, deep, and highly complex phraseological iceberg, and 'formulaicity' is not and, arguably, should not be reduced to 'items', but rather 'familiar language'. If this is the case, any discussion of 'holistic storage' and 'single choices' may be something of a red herring, particularly when it comes to L2 pedagogy. A simplistic item-based view of MWEs - a spirit in which the Idiom Principle is often interpreted-may lead to the belief that simply committing a certain number of expressions to memory will lead to attaining the same processing advantages reported in this article among native speakers, when, in fact, those processing advantages are probably more of an artifact of those speakers' iterative exposure to repeated patterns in different (or repeated) contexts.

Indeed, there is growing evidence for this 'lexical priming' (Hoey 2005) effect in the acquisition of MWEs. Li and Schmitt (2009), for example, tracked the acquisition of academic MWEs in the written production of a Chinese learner studying in a UK university. What the researchers found was that there was a positive relationship with the accuracy and breadth with which genre-appropriate MWEs were produced and a cumulative increase in academic readings to which the participant was exposed. Likewise, Webb et al. (2013) observed significant gains in MWE knowledge (in this case, collocations) as a function of repeated reading (while listening), and Martinez (2013) has provided evidence of a positive association between time spent engaged in extensive reading and even television viewing in English and knowledge of MWEs. This emerging story that extensive 'engagement' (Schmitt 2010: 26) with the L2 can lead to acquisition of MWEs should actually be unremarkable; indeed, we have known this for years about the acquisition of words through learner involvement with various types of input and interaction. What, perhaps, these newer studies point to is that it is not only words that are encoded (while reading, for example), but also the 'contexts and co-texts' (including, for example, genre-related information), which become 'cumulatively loaded' onto that encoding (Hoey 2005: 8), positively affected and reinforced by extensive reading and listening. 


\section{CONCLUSION}

In summary, it would seem that Sinclair's Idiom Principle could find empirical validation, but is clearly more complex than that theory seems to suggest. Yes, empirical psycholinguistic evidence does point to a processing advantage for native speakers when retrieving MWEs from memory, but the extent to which that processing advantage is tantamount to those items constituting 'single choices' is another matter. The degree to which MWEs are, in Wray's terms (2002: 9), 'stored, retrieved whole from memory' without recourse to constituent parts appears to largely depend on a number of variables, such as frequency and even compositionality-and focusing on this aspect of MWEs may distract from the important underlying drivers of formulaicity in language in the first place.

While the Idiom Principle as a metaphor has undoubtedly helped to swing the pendulum away from the predominant focus on single orthographic words in lexical research, it is perhaps time to move beyond notions of 'holistic storage' and explore in greater depth the mechanisms involved in acquiring the processing advantages that appear to exist among native speakers. It is only in our greater understanding of that phenomenon that we will be able to, as second language educators, investigate how we can best guide our learners to enjoy the same advantages.

\section{ACKNOWLEDGEMENTS}

We are grateful to the three anonymous Reviewers for their helpful and insightful comments on the previous version of this article.

\section{NOTES}

1 We define on-line processing as processing happening in real time. Online studies contrast with off-line ones (e.g., corpus studies). In on-line studies, reaction times and/or brain activity are recorded while participants perform a task in a laboratory setting under significant time pressure.

2 While the first part of the claim ('has available to him') is clearly important, a thorough operationalisation of the constructs implicit in that claim lies outside the scope of this article. The focus of this article will be chiefly restricted to the second part of the assertion concerning 'single choices'.

3 It needs to be pointed out that while many MWEs are indeed frequent, some MWEs-for example, idiomsexhibit relatively low frequencies as demonstrated in a number of corpusbased studies (e.g., Moon 1998). Nevertheless, idioms, arguably the most prototypical type of MWEs, are considered to be highly familiar and conventional. This could be attributed to the fact that given their idiosyncrasy and salience, even a dozen of occurrences will be sufficient to render them familiar, while in the case of other less idiosyncratic MWEs (e.g., collocations and lexical bundles), a lot more occurrences may be needed to make these MWEs conventional. In addition, as pointed out by SiyanovaChanturia et al. (2011a), due to idiom 
length (in some cases, up to eight or even more words), idiom frequency cannot be directly compared with that of single words or shorter MWEs. In Siyanova-Chanturia et al. (201la), the longest idioms were also the least frequent as attested in the British National Corpus (BNC) (e.g., you can't judge a book by its cover, see which way the wind is blowing, leave a bad taste in your mouth, etc.). Nonetheless, these idioms were found to be familiar to native, as well as non-native, speakers. It is noteworthy that the interplay between frequency and familiarity has not yet been fully understood; however, our stance is that frequency leads to familiarity and hence should be deemed as a primary characteristic of MWEs. Regardless, MWE frequency is a relative concept. The above discussion further underlines the challenges of finding and operationalising empirical criteria that can be used to define MWEs.

4 Usage- and exemplar-based accounts are often referred to as 'empiricist'

\section{REFERENCES}

Abbot-Smith, K. and M. Tomasello. 2006. 'Exemplar-learning and schematization in a usage-based account of syntactic acquisition,' The Linguistic Review 23: 275-90.

Arnon, I. and E.V. Clark. 2011. 'When 'on your feet' is better than 'feet': Children's word production is facilitated in familiar sentenceframes,' Language Learning and Development 7 : 107-29.

Arnon, I. and P.U. Cohen. 2013. 'More than words: The effect of multi-word frequency and constituency on phonetic duration,' Special Issue: Parsimony and Redundancy in Usage-Based Models of Linguistic Knowledge, Language and Speech 56/3: 257-64.

Arnon, I. and M. Ramscar. 2012. 'Granularity and the acquisition of grammatical gender: How order-of-acquisition affects what gets learned,' Cognition 122: 295-305. theories, at the heart of which lies the proposition that the basic unit of language acquisition is a construction, defined as 'associations between a semantic frame and a syntactic pattern, for which the meaning or form is not strictly predictable from its component parts' (Borensztajn et al. 2009: 175). In line with these theories, language learners start off not with single words, but with simple and concrete constructions gradually moving towards more complex and abstract ones (Borensztajn et al. 2009).

5 According to Manning and Schutze (1999), MI is a kind of 'measure of how much one word tells us about another' (p. 178). In practical terms, a high MI score indicates that when one word appears, it is likely that it will also appear with the other. An example is the word 'torrential' which is strongly associated with 'rain', and therefore 'torrential rain' would usually be assigned a high MI score in most corpora.

Arnon, I. and N. Snider. 2010. 'More than words: Frequency effects for multi-word phrases,' Journal of Memory and Language 62: 67-82.

Balota, D.A. and J.I. Chumbley. 1984. 'Are lexical decisions a good measure of lexical access? The role of word frequency in the neglected decision stage,' Journal of Experimental Psychology: Human Perception e Performance 10: 340-57.

Balota, D., A. Pollatsek, and K. Rayner. 1985. 'The interaction of contextual constraints and parafoveal visual information in reading,' Cognitive Psychology 17: 364-90.

Bannard, C. and D. Matthews. 2008. 'Stored word sequences in language learning: The effect of familiarity on children's repetition of four-word combinations,' Psychological Science 19: $241-48$. 
Bell, A., D. Jurafsky, E. Fosler-Lussier, C. Girand, M. Gregory, and D. Gildea. 2003. 'Effects of disfluencies, predictability, and utterance position on word form variation in English conversation,' The Journal of the Acoustical Society of America 113: 1001-24.

Biber, D., S. Johansson, G. Leech, S. Conrad, and E. Finegan. 1999. Longman Grammar of Spoken and Written English. Longman.

Bobrow, S. and S. Bell. 1973. 'On catching on to idiomatic expressions,' Memory and Cognition 1/3: 343-6.

Bod, R. 1998. Beyond Grammar: An ExperienceBased Theory of Language. Center for the Study of Language and Information.

Bod, R. 2006. 'Exemplar-based syntax: How to get productivity from exemplars,' The Linguistic Review 23: 291-320.

Bod, R., J. Hay, and S. Jannedy. 2003. 'Introduction' in R. Bod, J. Hay, and S. Jannedy (eds): Probabilistic Linguistics. The MIT Press, pp. 1-10.

Boers, F., J. Eyckmans, J. Kappel, H. Stengers, and M. Demecheleer. 2006. 'Formulaic sequences and perceived oral proficiency: Putting a Lexical Approach to the test,' Language Teaching Research 10/3: 245-61.

Borensztajn, G., W. Zuidema, and R. Bod. 2009. 'Children's grammars grow more abstract with age-evidence from an automatic procedure for identifying the productive units of language,' Topics in Cognitive Science 1: 175-88.

Bybee, J. 1985. Morphology: Study of Relation Between Meaning and Form. Benjamins.

Bybee, J. 1995. 'Regular morphology and the lexicon,' Language and Cognitive Processes 10/5: 425-55.

Bybee, J. 1998. 'The mergent lexicon,' Chicago Linguistic Society 34: 421-35.

Bybee, J. 2006. 'From usage to grammar: The mind's response to repetition,' Language 82/4: 711-33.

Bybee, J. and J. Scheibman. 1999. 'The effect of usage on degree of constituency: The reduction of don't in American English,' Linguistics 37: 575-96.

Cacciari, C. and P. Tabossi. 1988. 'The comprehension of idioms,' Journal of Memory and Language 27: 668-83.

Cieslicka, A. 2006. 'Literal salience in on-line processing of idiomatic expressions by second language learners,' Second Language Research 22: 115-44.

Conklin, K. and N. Schmitt. 2008. 'Formulaic sequences: Are they processed more quickly than nonformulaic language by native and non-native speakers?,' Applied Linguistics 29: 72-89.

Croft, W. 2001. Radical Construction Grammar: Syntactic Theory in Typological Perspective. Oxford University Press.

Croft, W. and D. Cruse. 2004. Cognitive Linguistics. Cambridge University Press.

Cutting, J. and K. Bock. 1997. 'That's the way the cookie bounces: Syntactic and semantic components of experimentally elicited idiom blends,' Memory and Cognition 25/1: 57-71.

Dunn, L.M. and D.M. Dunn. 2007. The Peabody Picture Vocabulary Test (PPVT-IV). Pearson.

Ellis, N. 2002. 'Frequency effects in language processing,' Studies in Second Language Acquisition 24/2: 143-88.

Ellis, N.C. 2011. 'Frequency-based accounts of SLA $^{\prime}$ in S. Gass and A. Mackey (eds): Handbook of Second Language Acquisition. Routledge/Taylor Francis, pp. 193-210.

Ellis, N.C. 2012. 'What can we count in language, and what counts in language acquisition, cognition, and use?' in S. Th. Gries and D.S. Divjak (eds): Frequency Effects in Language Learning and Processing, vol. 1. Mouton de Gruyter, pp. 7-34.

Ellis, N.C. and M. O'Donnell. 2012. 'Statistical construction learning: Does a Zipfian problem space ensure robust language learning?' in J. Rebuschat and J. Williams (eds): Statistical Learning and Language Acquisition. Mouton de Gruyter, pp. 265-304.

Engbert, R., A. Nuthmann, E. Richter, and R. Kliegl. 2005. 'SWIFT: A dynamical model of saccade generation during reading,' Psychological Review 112: 777-813.

Erman, B. and B. Warren. 2000. 'The idiom principle and the open choice principle,' Text 20/1: 29-62.

Firth, J. 1957. 'A synopsis of linguistic theory, 1930-1955,' in Studies in Linguistic Analysis. Blackwell, pp. 1-32.

Forster, K. 1976. 'Accessing the mental lexicon' in R. Wales and E. Walter (eds): New Approaches to Language Mechanisms. North Holland Publishing, pp. 257-84.

Foster, P. 2001. 'Rules and routines: A consideration of their role in the task-based language 
production of native and non-native speakers' in M. Bygate, P. Skehan, and M. Swain (eds): Researching Pedagogic Tasks: Second Language Learning, Teaching, and Testing. Longman, pp. 75-94.

Geluso, J. 2013. 'Phraseology and frequency of occurrence on the web: Native speakers' perceptions of Google-informed second language writing,' Computer Assisted Language Learning 26/2: 144-57.

Gibbs, R. 1980. 'Spilling the beans on understanding and memory for idioms in conversation,' Memory and Cognition 8: 449-56.

Gibbs, R. and G. Gonzales. 1985. 'Syntactic frozenness in processing and remembering idioms,' Cognition 20: 243-59.

Gibbs, R., N. Nayak, and C. Cutting. 1989. 'How to kick the bucket and not decompose: Analyzability and idiom processing,' Journal of Memory and Language 28: 576-93.

Glucksberg, S. 1989. 'Metaphors in conversation: How are they understood?' Why are they used?,' Metaphor and Symbolic Activity 4: 125-43.

Goldberg, A. 1995. Constructions. University of Chicago Press.

Goldberg, A. 2006. Constructions at Work: The Nature of Generalization in Language. Oxford University Press.

Granger, S. 1998. 'Prefabricated patterns in advanced EFL writing: Collocations and formulae' in A.P. Cowie (ed.): Phraseology: Theory, Analysis, and Applications. Oxford University Press, pp. 79-100.

Gregory, M., W. Raymond, A. Bell, E. FoslerLussier, and D. Jurafsky. 1999. 'The effects of collocational strength and contextual predictability in lexical production,' Chicago Linguistic Society 35: 151-66.

Hoey, M. 2005. Lexical Priming: A New Theory of Words and Language. Routledge.

Howarth, P. 1998. 'The phraseology of learners' academic writing' in A. Cowie (ed.): Phraseology: Theory, Analysis and Applications. Oxford University Press, pp. 161-86.

Janssen, N. and H. Barber. 2012. 'Phrase frequency effects in language production,' PLoS One 7/3: e33202. doi:10.1371/ journal.pone.0033202.

Jurafsky, D. 1996. 'A probabilistic model of lexical and syntactic access and disambiguation,' Cognitive Science 20: 137-94.

Jurafsky, D. 2003. 'Probabilistic modeling in psycholinguistics: Linguistic comprehension and production' in R. Bod, J. Hay, and S. Jannedy (eds): Probabilistic Linguistics. The MIT Press, pp. 39-95.

Konopka, A. and K. Bock. 2009. 'Lexical or syntactic control of sentence formulation? Structural generalizations from idiom production,' Cognitive Psychology 58/1: 68-101.

Langacker, R. 1987. Foundations of Cognitive Grammar, vol. 1. Stanford University Press.

Li, J. and N. Schmitt. 2009. 'The acquisition of lexical phrases in academic writing: A longitudinal case study,' Journal of Second Language Writing 18/2: 85-102.

MacWhinney, B., E. Bates, and R. Kliegl. 1984. 'Cue validity and sentence interpretation in English, German, and Italian,' Journal of Verbal Learning and Verbal Behavior 23/2: 127-50.

Manning, C. and H. Schutze. 1999. Foundations of Statistical Natural Language Processing. MIT Press.

Martinez, R. 2013. How Does (a Lack of) Knowledge of Multiword Expressions Affect Reading Comprehension? The American Association of Applied Linguistics Convention.

Martinez, R. and V. Murphy. 2011. 'Effect of frequency and idiomaticity on second language reading comprehension,' TESOL Quarterly 45/2: 267-90.

Martinez, R. and N. Schmitt. 2012. 'A phrasal expressions list,' Applied Linguistics 33/3: 299-320.

McDonald, S. and R. Shillcock. 2003a. 'Lowlevel predictive inference in reading: The influence of transitional probabilities on eye movements,' Vision Research 43: 1735-51.

McDonald, S. and R. Shillcock. 2003b. 'Eye movements reveal the on-line computation of lexical probabilities during reading,' Psychological Science 14/6: 648-52.

Meunier, F. and S. Granger. 2008. Phraseology in Foreign Language Learning and Teaching. John Benjamins.

Millar, N. 2011. 'The processing of malformed formulaic language,' Applied Linguistics 32/2: 129-48.

Miller, G. 1956. 'The magical number seven, plus or minus two: Some limits on our capacity for processing information,' The Psychological Review 63: 81-97.

Moon, R. 1998. Fixed Expressions and Idioms in English. Clarendon Press. 
Monsell, S., M. Doyle, and P. Haggard. 1989. 'Effects of frequency on visual word recognition tasks: Where are they?' Journal of Experimental Psychology: General 118: 43-71.

Nesselhauf, N. 2003. 'The use of collocations by advanced learners of English and some implications for teaching,' Applied Linguistics 24/2: 223-42.

Nesselhauf, N. 2004. Collocations in a Learner Corpus. John Benjamins.

Peterson, R., C. Burgess, G. Dell, and K. Eberhard. 2001. 'Disassociation between syntactic and semantic processing during idiom comprehension,' Journal of Experimental Psychology: Learning, Memory, and Cognition 27/5: 1223-37.

Pickering, M.J. and S. Garrod. 2007. 'Do people use language production to make predictions during comprehension?,' Trends in Cognitive Sciences 11/3: 105-10.

Pierrehumbert, J. 2001. 'Exemplar dynamics: Word frequency, lenition and contrast' in J. Bybee and P. Hopper (eds): Frequency and the Emergence of Linguistic Structure. John Benjamins, pp. 137-57.

Pollio, H., J. Barlow, H. Fine, and M. Pollio. 1977. Psychology and the Poetics of Growth: Figurative Language in Psychology, Psychotherapy, and Education. Lawrence Erlbaum.

Rayner, K. and S. Duffy. 1986. 'Lexical complexity and fixation times in reading: Effects of word frequency, verb complexity, and lexical ambiguity,' Memory and Cognition 14: 191-201.

Rayner, K. and A. Well. 1996. 'Effects of contextual constraint on eye movements in reading: A further examination,' Psychonomic Bulletin and Review 3/4: 504-9.

Reichle, E., Pollatsek, A., Fisher, D., and Rayner, K. 1998. 'Toward a model of eye movement control in reading,' Psychological Review 105: 125-57.

Saussure, F. De. 1916/1966. Course in General Linguistics. McGraw-Hill.

Schmitt, N. 2010. Researching Vocabulary: A Vocabulary Research Manual. Palgrave Macmillan.

Schmitt, N., D. Schmitt, and C. Clapham. 2001. 'Developing and exploring the behaviour of two new versions of the Vocabulary Levels Test,' Language Testing 18/1: 55-88.
Segalowitz, N. 2003. 'Automaticity and second languages' in M. Long and C. Doughty (eds): The Handbook of Second Language Acquisition. Blackwell, pp. 382-408.

Seidenberg, M. and M. MacDonald. 1999. 'A probabilistic constraints approach to language acquisition and processing,' Cognitive Science 23/4: 569-88.

Simpson-Vlach, R. and N.C. Ellis. 2010. 'An academic formulas list: New methods in phraseology research,' Applied Linguistics 31: 487-512.

Sinclair, J. 1991. Corpus, Concordance, Collocation. Oxford University Press.

Siyanova, A. and N. Schmitt. 2007. 'Native and nonnative use of multi-word versus one-word verbs,' International Review of Applied Linguistics 45: 119-39.

Siyanova, A. and N. Schmitt. 2008. 'L2 learner production and processing of collocation: A multi-study perspective,' The Canadian Modern Language Review 64/3: 429-58.

Siyanova-Chanturia, A., K. Conklin, and N. Schmitt. 2011a. 'Adding more fuel to the fire: An eye-tracking study of idiom processing by native and nonnative speakers,' Second Language Research 27: 251-72.

Siyanova-Chanturia, A., K. Conklin, and W. van Heuven. $2011 \mathrm{~b}$. 'Seeing a phrase 'time and again' matters: The role of phrasal frequency in the processing of multi-word sequences,' Journal of Experimental Psychology: Language, Memory, and Cognition 37/3: 776-84.

Sorhus, H. 1977. 'To hear ourselvesImplications for teaching English as a second language,' ELT Journal 31: 211-21.

Sosa, A. and J. MacFarlane. 2002. 'Evidence for frequency-based constituents in the mental lexicon: Collocations involving the word of,' Brain and Language 83: 227-36.

Sprenger, S., W. Levelt, and G. Kempen. 2006. 'Lexical access during the production of idiomatic phrases,' Journal of Memory and Language 54: 161-84.

Swiney, D. and A. Cutler. 1979. 'The access and processing of idiomatic expressions,' Journal of Verbal Learning and Verbal Behaviour 18: 523-34.

Titone, D. and C. Connine. 1999. 'One the compositional and noncompositional nature of idiomatic expressions,' Journal of Pragmatics 31: 1655-74. 
Tomasello, M. 2003. Constructing a Language: A Ssage-Based Theory of Language Acquisition. Harvard University Press.

Tomasello, M. 2006. 'Acquiring linguistic constructions' in W. Damon, R. Lerner, D. Kuhn, and R. Siegler (eds): Handbook of Child Psychology, vol. 2, 6th edn. Wiley, pp. 255-98.

Tremblay, A., B. Derwing, G. Libben, and C. Westbury. 2011. 'Processing advantages of lexical bundles: Evidence from self-paced reading and sentence recall tasks,' Language Learning 61/2: 569-613.

Underwood, G., N. Schmitt, and A. Galpin. 2004. 'The eyes have it: An eye-movement study into the processing of formulaic sequences' in N. Schmitt (ed.): Formulaic Sequences. John Benjamins, pp. 153-72.

Van Lancker, D., G. Canter, and D. Terbeek. 1981. 'Disambiguation of ditropic sentences: Acoustic and phonetic cues,' Journal of Speech and Hearing Research 24: 330-5.

Webb, S., J. Newton, and A. Chang. 2013. 'Incidental learning of collocation,' Language Learning 63/1: 91-120.

West, M. 1953. A General Service List of English Words. Longman.

Wray, A. 2002. Formulaic Language and the Lexicon. Cambridge University Press. 